Research Paper:

\title{
Self-awareness Skill Training of Mothers as the Head of the Household and the Self-efficacy of Their Sons
}

\author{
Maliheh Aziznejad $^{1} \odot$, Sara Janmohammadi ${ }^{* *} \odot$ Marhamat Farahaninia $^{2} \odot$, Hamid Haghani ${ }^{1} \odot$ \\ 1. Department of Community Health Nursing, School of Nursing and Midwifery, Iran University of Medical Sciences, Tehran, Iran. \\ 2. Department of Biostatistics, School of Public Health, Iran University of Medical Sciences, Tehran, Iran.
}

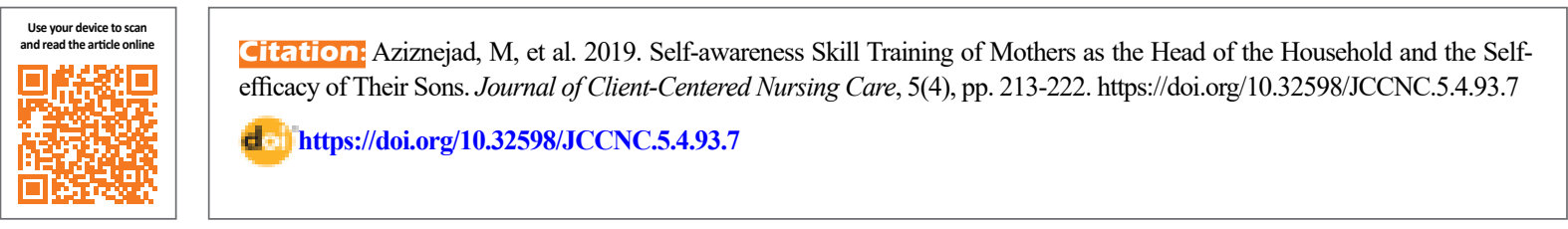

() 03

Article info:

Received: 10 May 2019

Accepted: 03 Sep 2019

Published: 01 Nov 2019
Keywords:

Training, Self-awareness skill, Self-efficacy, Mothers as the head of the household, Sons

\section{A B S T RA C T}

Background: The adults' life is rooted in their childhood. Children living in single-parent families have less self-efficacy than others. Educating self-awareness skill reliance on the family is among the key aspects of self-efficacy promotion in early childhood. The present study aimed to determine the effect of self-awareness training of the mothers as the head of the household on the self-efficacy of their 10- to 12-year-old sons.

Methods: This was a quasi-experimental study with a Pre-test-Post-test and a control group design. The study sample consisted of 10 - to 12-year-old boys $(\mathrm{N}=71)$ from public schools of Ray City, Iran, and their heads of the family mothers. The study subjects were randomly assigned to the experimental and control groups. The Pre-test was administered to both groups. Then, the mothers of the intervention group attended four 45-minute training sessions twice a week. Moreover, the Post-test was administered to the groups three months after the end of the intervention. The required data were collected by demographic characteristics form, SelfConsciousness Scale (SCS), and Self-efficacy Questionnaire for Children (SEQ-C). Furthermore, the obtained data were analyzed by descriptive statistics, including frequency distribution, mean and standard deviation, and inferential statistics, including the Chi-squared test, Fisher's Exact test, Independent Samples t-test, Paired Samples t-test, and Analysis of Covariance (ANCOVA) using SPSS.

Results: The study results suggested a significant difference in self-awareness Mean \pm SD scores of the mothers in the intervention group before $(41.77 \pm 10.59)$ and after $(53.83 \pm 8.43)$ conducting the intervention $(\mathrm{P}<0.001)$; however, such difference was not significantly different in the control group before (47.31 \pm 12.45$)$ and three months after the intervention (47.05 \pm 11.76$)$. There was a significant difference between the self-efficacy Mean \pm SD scores of boys in the intervention group before $(61.88 \pm 9.29)$ and after $(70.44 \pm 8.12)$ providing the intervention $(\mathrm{P}<0.001)$; however, this difference was not significantly different in the control group before $(65.68 \pm 11.33)$ and after the intervention provision $(65.14 \pm 12.01)$

Conclusion: In this study, mothers' self-awareness positively affected their sons' self-efficacy. Thus, self-awareness enabled mothers to identify the emotions of themselves and their children and become aware of them and pay more attention to interacting with their children. These findings help school health nurses in providing a proper educational environment with the collaboration of mothers who are the head of the family.

\section{* Corresponding Author:}

Sara Janmohammadi, MSc.

Address: Department of Community Health Nursing, School of Nursing and Midwifery, Iran University of Medical Sciences, Tehran, Iran. Tel: +98 (21) 43651804

E-mail: Janmohammadi.s@iums.ac.ir 


\section{Highlights}

- The school health nurses help to promote community healthcare, prevent diseases, and ultimately alleviate illnesses in the educational environment of schools.

- The current study determined the effect of self-awareness training in the mothers who are the head of the family on the self-efficacy of their 10- to 12-year-old sons.

- The obtained results indicated that the self-efficacy score of 10- to 12-year-old boys increased after self-awareness training was provided to their mothers.

- Providing training classes on self-awareness and self-efficacy is recommended to educational planners as a lowcost, feasible, and accessible approach to target groups, including students and parents.

\section{Plain Language Summary}

Children in single-parent families spend less time with their parents, compared to nuclear families; as a result, they may suffer weakness in performance and competence. More than $20 \%$ of students in Iran suffer from personal problems, such as low capability and family issues. According to the general population and housing census of 2016, the age group of $0-14$ years constitutes $24 \%$ of the country's population. Some families in the country include a singleparent, and of these families, $83 \%$ are managed by females. This study discussed the effect of self-awareness skill training in the mothers who are the head of the family on the self-efficacy of their 10- to 12-year-old sons. Based on the collected results, self-awareness skill training was effective in self-efficacy. Accordingly, educational program planners could use this method to promote mental health as well as self-efficacy in single-parent children.

\section{Introduction}

hildhood is the first and most crucial period of human life. During this period, a child communicates with nature for the first time, builds social relationships, and achieves a concept of self (Piri \& Adib 2009). The speed of learning and development in childhood is more than any other life stage, and the experiences of this period form the basis of future education; therefore, childhood is of particular importance and sensitivity. Children are vulnerable and are unable to take care of themselves; thus, parents' support and protection from birth to childhood onwards are essential for their survival. Parents have historically been responsible for the care, discipline, and management of their children and are one of the preliminary and fundamental factors in the transformation and socialization of children (Abbasi, Asgari \& Mehrabi 2015).

Family, as a sacred structure, is the first, most important, and principal orphanage and academy. Parents shape the family environment by preparing children with new challenges and experiences. Parental expectations and perceptions of children's abilities could influence and develop children's self-efficacy (Gardner 2011). Children need skills that influence their process of development and helps them to cope with different situations and life issues. Skills, like recognizing emotions and behaviors, are manifested in the structures, such as self-esteem, selfefficacy, problem-solving ability, coping, self-perception, and social skills (Delbery 2015).

A social life issue is being orphaned or having a singleparent in children. Single-parent children and adolescents have lost one of their parents due to incidents, such as car accidents, death, divorce, and so on (Eslami et al. 2013). Children living in single-parent families, due to educational and psychological deprivations and ineffective support of parents have lower self-efficacy than others. The absence of a father could have a direct (e.g. deprivation from a male role model) and indirect (e.g. support) influence on children (Nelson 2013).

Absence of father in single-parent families, i.e., managed by a female, forces the mothers to bear the financial burden of family and children. As a result, these mothers have less opportunity to care for their children. Children in single-parent families spend less time with their mother or father than nuclear families; consequently, they have decreased self-esteem and self-efficacy (Ghaemi 2007). 
Self-efficacy, as one of the core concepts in cognitive-social theory, has been the focus of numerous professionals (Niknam 2011). Self-efficacy, which increases throughout childhood and early adulthood (Chabok, Kashaninia \& Haghani 2017) prepare individuals' for challenging and ambiguous situations, provides context for identifying real capacities, and enhances self-esteem and acceptance of self (Yousefzadeh, Yaghoobi \& Rashidi 2012).

Most individuals tend to blame parents for having a indecent, hyperactive, and unsuccessful child, as well as the problems they cause. To resolve these issues, experts consider parent education to be effective, and necessary for a desirable life (Zajeri 2011). Most behavioral problems could be traced in childhood and due to the importance of this life stage, mothers' education and application of a set of communication skills are essential for their proper interaction with children (Tork-Ladani et al. 2013). Education promotes individuals' cognitive development and helps them to solve life problems (Zajeri 2011) efficiently. Studies have reported that parenting education program improves children's adaptability and reduces their behavioral issues. Additionally, life skills training is effective in enhancing parental self-efficacy as well as interaction with their children (Tork-Ladani et al. 2013).

Parent group education is a training that consists of extensive instructions and helps parents to learn the knowledge and abilities in the field of child disciplining. Parent education programs, through providing appropriate information about children's condition and behavioral strategies, lead parents to have a more effective role in the child's development, which in turn, increases children's self-efficacy (Taklavi 2012).

Based on the results of several assessments, self-awareness skill is a priority in education (Sahraian, Solhi, \& Haghani 2012). Self-awareness skill is defined as the ability to understand features, needs, feelings, fears, disgust, hatred, interests, pressures, shortcomings, satisfaction, empathy, strengths and weaknesses, as well as individual traits (Sharifnasab \& Sadrizade 2011). Selfawareness skill is a predictor of self-efficacy and its learning increases self-efficacy. There is also evidence that high levels of life skills prevent stress effects by increasing self-efficacy (Jahani Maleki et al. 2011).

Among family members, mothers have the first biological and vital connection with their child; accordingly, they significantly impact the child's personality development. In Eastern societies, mothers carry the role of caring for their children's biopsychosocial needs, and fathers are less likely to engage with children (Grant,
2001). The current study aimed at determining the effect of self-awareness training provided to mothers who are the head of the family on the self-efficacy of their 10- to 12-year-old sons.

\section{Materials and Methods}

This was a quasi-experimental study with a Pre-testPost-test and a control group design. Inclusion criteria were willingness to participate in the research, being a mother who is the head of the family, having Iranian nationality, being literate, and the lack of substance dependence. Exclusion criteria were unwillingness to continue the study or not attending one training session.

A permission was received from the Ethics Committee on Research of Iran University of Medical Sciences (IUMS) and the approval of the research council. The researcher provided the mothers and students with the necessary information, such as the study objectives, duration of the study, explanations on the study conduction, and that their participation was voluntary. Non-participation did not affect their educational process, only using the obtained information for the present study purposes, providing the results to the mothers and students after the study upon their request, and putting the educational content at the disposal of the control group after the study completion.

The mothers and students who agreed to participate in the study signed informed consent. The study sample consisted of 71 mothers who were the head of the family and their sons, selected by convenience sampling technique from 13 different boys' elementary schools (35 in the control group, 36 in the intervention group). The required sample size was calculated at a $95 \%$ confidence level and test power of $80 \%$, assuming that the effect of self-awareness skill training to mothers on their sons' self-efficacy was at least $\mathrm{d}=4$; therefore, the effect of training was statistically significant. Accordingly, the required sample size was estimated as $n=35$ per group and considering the $10 \%$ sample attrition, $n=40$ mothers as the head of the family and their sons were considered as the study subjects. The training sessions were conducted in one of the schools.

The data collection tool included the demographic data form, Self-Consciousness Scale (SCS) and Self-Efficacy Questionnaire for Children (SEQ-C). Demographic data form for the mothers included age, the number of children, childbirth rank, educational level, occupation, economic status, residential house type, and being covered by supporting organizations. For the boys, it included age and the grade of education. 
SCS consists of 23 statements to be responded on a 5-point Likert-type scale, indicating how accurately a given statement describes the subjects' experiences and behaviors (from 0: totally inaccurate, to 4: totally accurate). The questionnaire is divided into three subscales, including: private self-consciousness (10 statements), public self-consciousness (8 statements), and social anxiety ( 5 statements). The total score is obtained by summing all items' scores. Three items of this questionnaire have a reverse score (items $3,9,12$ ). The minimum and maximum obtainable scores are 0 and 92, respectively. Higher scores on each subscale of the SCS indicate higher private self- consciousness, public self-consciousness, and social anxiety (Fenigstein, Scheier \& Buss 1975). The reliability coefficient of this scale using Cronbach's alpha coefficient was reported as 0.71 for private self-awareness, 0.57 for public self-awareness, and 0.84 for social anxiety; indicating its acceptable internal consistency. The validity and reliability of the questionnaire have been confirmed in Iran (Latifian \& Seif 2007; Hosseini et al. 2008).

In this study, the scale's Cronbach's alpha coefficient was calculated to examine its internal consistency. It was obtained as 0.70 for the general category and 0.63 to 0.70 for the subcategories (private: 0.70 , public: 0.69 , social anxiety: 0.63 ). A test-retest reliability assessment was used to determine the reliability of the tool with a 2-week interval.

SEQ-C consists of 23 items, responded on a 5-point Likert-type scale (from 1: not at all, to 5: very well). The tool measures self-efficacy in 3 dimensions, including academic self-efficacy: items 1-8, social self-efficacy: items 9-16, and emotional self-efficacy: items 17-23. The total self-efficacy score is obtained by summing all achieved items. The minimum and maximum obtainable scores are 23 and 115, respectively. The score of each subscale is obtained by summing up the scores of responses to the questions of that subscale. The score of every question ranges from 1 to 5 (Muris 2001; Muris 2002).

The validity of the Persian version of the questionnaire was assessed in Iran by content validity examination, and its reliability for the general category was calculated as 0.89 using a test-retest technique (Tahmaseian \& Anari 2009). In the current study, the reliability of the questionnaire was calculated by the test-retest method as 0.88 .

In the present study, pre-test, post-test evaluations were administered to both study groups. The sampling method in this study was a non-randomized and consecutive sampling technique adjusted for gender. We achieved permission to constitute a training class by the Depart- ment of Education for one of the schools; to prevent information contamination and to isolate the groups, the intervention group participants were selected from the same school and 6 schools that were close to it. The control group samples were also selected from other schools. Oral explanations of the questions were provided to the research samples to complete the questionnaires.

To prevent any inconvenience for the participants, the survey was conducted at the time of the classes and according to the opinion of the majority of the study subjects (the classes were held from 8 to $8: 45 \mathrm{AM}$ ). The mothers of the intervention group were informed by telephone about the place, time, and dates of the training classes.

The mothers of the intervention group received selfawareness training. Text messages were also sent to the intervention group to remind the class the day before each session. Training sessions initiated based on a booklet. Before conducting the intervention, the validity of the booklet contents was approved by the faculty members of the school of nursing. According to the scheduled timetable, four 45-minute sessions were held twice a week using powerpoint slides. The training was conducted by the researcher in one of the schools with an interactive lecture method. Moreover, during the last meeting, a pamphlet containing a summary of the contents of all sessions was provided to the intervention group.

The intervention lasted two weeks. During the training sessions or at the end of each training session, pre-prepared leaflets containing challenging questions about the topic regarding the same session and the next session assignment were given to the study participants. Paper works were collected at the beginning of each session and were briefly discussed. The contents provided in each session are listed in Table 1. Furthermore, the mothers of the control group and the students in the intervention and control groups received no training. Three months after the end of the sessions, the questionnaires were re-completed in both groups. In addition, after the end of the study, the discussed content was provided to the control group. Data analysis was performed by frequency distribution tables, numerical indexes, as well as the Chi-squared test, Fisher's Exact test, t-test, Paired Samples t-test, and Analysis of Covariance (ANCOVA) using SPSS.

Independent Samples t-test was used to compare the selfawareness and self-efficacy Pre-test-Post-test scores in the experimental and control groups. Furthermore, the Paired Samples t-test was used to compare self-awareness and selfefficacy Pre-test-Post-test scores in each group $(\mathrm{P}<0.001)$. 
Table 1. Contents provided in the training sessions

\begin{tabular}{cc}
\hline $\begin{array}{c}\text { Number of } \\
\text { Sessions }\end{array}$ & Issues Provided per Session \\
\hline First & $\begin{array}{c}\text { Introduction, a description of the rules for attending meetings and the purpose of providing education, defining and } \\
\text { acquainting with self-awareness skills, presenting the concept of self, types of self, and the introduction of the real self } \\
\text { and the ideal self. }\end{array}$ \\
Second & $\begin{array}{r}\text { Reviewing prior session matters and providing feedback, expressing the necessities of self-awareness training and } \\
\text { learning, the benefits of self-awareness, factors affecting the growth of self-awareness, and barriers to self-aware- } \\
\text { ness. }\end{array}$ \\
Third & $\begin{array}{r}\text { Reviewing prior session content and providing feedback, the components of self-awareness (recognize features, } \\
\text { abilities and skills, weaknesses points, thoughts, beliefs, and values, \& goals) }\end{array}$ \\
Fourth & $\begin{array}{r}\text { Reviewing prior session points and providing feedback, the components of self-awareness (recognizing one's } \\
\text { feelings, identity, and identification, \& self-esteem), reviewing and summarizing topics discussed throughout the } \\
\text { sessions. }\end{array}$ \\
\hline
\end{tabular}

Client- Centered Nursing Care

\section{Results}

There was no significant difference between the studied groups (mothers as the head of the family) in terms of age $(\mathrm{P}=0.431)$, the number of children $(\mathrm{P}=0.99)$, childbirth rank $(\mathrm{P}=0.335)$, educational level $(\mathrm{P}=0.754)$, occupation $(\mathrm{P}=0.561)$, economic status $(\mathrm{P}=0.999)$, residential house type $(\mathrm{P}=0.737)$, and being covered by support organizations $(\mathrm{P}=0.106)$. No significant difference was found between the age and educational grades $(\mathrm{P}=0.288)$ of their sons (Table 2).

There were no significant differences between the Mean \pm SD scores of private self-awareness $(21.11 \pm 7.11)$ and social anxiety $(11.28 \pm 4.20)$ in the control and intervention $(18.47 \pm 6.84,11.02 \pm 5.62)$ groups at Pretest $(\mathrm{P}=0.11, \mathrm{P}=0.82)$ respectively. However, there were significant differences between the Mean \pm SD scores of public $(14.91 \pm 5.40)$ and total self-awareness $(47.31 \pm 12.45)$ in the control and intervention (12.27 $\pm 5.01,41.77 \pm 10.59)$ groups $(\mathrm{P}=0.03, \mathrm{P}=0.04)$, respectively. The differences between the Mean \pm SD scores of the mothers as the head of the family's selfawareness and its dimensions were not significant before and after the study in the control group (47.05 \pm 11.76$)$ $(\mathrm{P}=0.43)$; however, such difference was significant in the intervention group $(53.83 \pm 8.43)(\mathrm{P}<0.001)$ (Table 3).

There was no significant difference between the Mean \pm SD scores of self-efficacy in the control $(65.68 \pm 11.33)$ and intervention $(61.88 \pm 9.29)$ groups $(\mathrm{P}=0.12)$ at Pre-test phase. The differences between the Mean \pm SD Pre-test-Post-test scores of the boys' self-efficacy and its dimensions were not significant in the controls $(65.14 \pm 12.01)(\mathrm{P}=0.12)$; however, this difference was significant in the intervention group $(70.44 \pm 8.12)$ $(\mathrm{P}<0.001)$ (Table 4).

\section{Discussion}

The current study aimed at investigating the effect of self-awareness skill training in the mothers who were the head of the family on the self-efficacy of their 10- to 12-year-old sons. The obtained data suggested that the Mean \pm SD scores of self-awareness and self-efficacy increased in the intervention group three months after the intervention $(\mathrm{P}<0.001)$. However, there were no significant differences between the Pre-test-Post-test scores in the controls.

No similar study was found in this area. However, Hatami et al. (2016) investigated the effect of self-awareness training focused on the self-efficacy of orphaned adolescents. They reported that after the intervention, the mean scores of self-awareness and self-efficacy significantly increased in the intervention group, compared to the control group at Post-tests; time was also a significant factor in these changes $(\mathrm{P}<0.001)$. Considering the time/ group factor, the trend of changes was significant in both groups $(\mathrm{P}<0.001)$. Furthermore, the results of the Pearson correlation coefficient revealed a direct linear correlation between self-awareness and self-efficacy at Posttest, and in weeks 1 and 6 post-intervention $(\mathrm{P}<0.001)$, i.e., in line with the present study results.

Sevari \& Manshedavi (2015) explored the efficacy of selfawareness training on the reduction of internet addiction and loneliness and increasing self-efficacy in Iran. They concluded that self-awareness skill training had increased self-efficacy in the experimental group. Umaru and Umma (2015) investigated the effect of emotional intelligence skills training on the locus of control and academic selfefficacy among junior secondary school students in Nigeria. The relevant data revealed that self-awareness training positively impacted the development of self-efficacy. 
Table 2. Demographic characteristics of the mothers as the head of the family and their sons in the intervention and control groups

\begin{tabular}{|c|c|c|c|c|}
\hline \multirow{2}{*}{ Variables } & \multirow{2}{*}{ Groups } & \multicolumn{2}{|c|}{ No. (\%) } & \multirow{2}{*}{ Test Results } \\
\hline & & Control & Intervention & \\
\hline \multirow{5}{*}{ Age (y) } & $30-34$ & $7(20.0)$ & $12(33.3)$ & \multirow{5}{*}{$\begin{array}{c}t=2.752 \\
d=3 \\
P=0.431 *\end{array}$} \\
\hline & $35-39$ & $9(25.7)$ & $7(19.4)$ & \\
\hline & $40-44$ & $9(25.7)$ & $11(30.6)$ & \\
\hline & $\geq 45$ & $10(28.6)$ & $6(16.7)$ & \\
\hline & & $40.82 \pm 6.85$ & $39.02 \pm 5.70$ & \\
\hline \multirow{4}{*}{$\begin{array}{l}\text { The number of } \\
\text { children }\end{array}$} & 1 & $13(37.1)$ & $13(36.1)$ & \multirow{4}{*}{$\begin{array}{c}t=0.02 \\
d f=2 \\
P=0.99^{*}\end{array}$} \\
\hline & 2 & $14(40.0)$ & $15(41.7)$ & \\
\hline & $\geq 3$ & $8(22.9)$ & $8(22.2)$ & \\
\hline & & $2.11 \pm 1.30$ & $1.88 \pm 0.82$ & \\
\hline \multirow{4}{*}{ Childbirth rank } & 1 & $21(60.0)$ & $19(52.8)$ & \multirow{4}{*}{$\mathrm{P}=0.335^{* *}$} \\
\hline & 2 & $7(20.0)$ & $13(36.1)$ & \\
\hline & 3 & $6(17.1)$ & $4(11.1)$ & \\
\hline & 4 & $1(2.9)$ & $0(0)$ & \\
\hline \multirow{4}{*}{ Level of education } & Primary school & $5(14.3)$ & $4(11.1)$ & \multirow{4}{*}{$\mathrm{P}=0.754^{* *}$} \\
\hline & Secondary school & $6(17.1)$ & 6 (16.7) & \\
\hline & Diploma & $21(60.0)$ & $25(69.4)$ & \\
\hline & Undergraduate or higher degree & $3(8.6)$ & $1(2.8)$ & \\
\hline & Housekeeper & $19(54.3)$ & $22(61.1)$ & $\chi^{2}=0.33$ \\
\hline uccupanton & Employed & $16(45.7)$ & $14(38.9)$ & $\begin{array}{c}\mathrm{dT}=1 \\
\mathrm{P}=0.561^{* * *}\end{array}$ \\
\hline \multirow{3}{*}{ Economic status } & Good & $1(2.9)$ & $2(5.6)$ & \multirow{3}{*}{$\mathrm{P}=0.999 * *$} \\
\hline & Medium & $17(48.6)$ & $17(47.2)$ & \\
\hline & Weak & $17(48.6)$ & $17(47.2)$ & \\
\hline \multirow{2}{*}{$\begin{array}{l}\text { Residential house } \\
\text { type }\end{array}$} & Owner & $13(37.1)$ & $12(33.3)$ & \multirow{2}{*}{$\begin{array}{c}\chi^{2}=0.113 \\
d f=1 \\
P=0.737^{* * *}\end{array}$} \\
\hline & Tenant & $22(62.9)$ & $24(66.7)$ & \\
\hline \multirow{2}{*}{$\begin{array}{l}\text { Being covered by } \\
\text { supporting organiza- } \\
\text { tions }\end{array}$} & Yes & $10(28.6)$ & $17(47.2)$ & \multirow{2}{*}{$\begin{array}{c}\chi^{2}=2.619 \\
d f=1 \\
P=0.106^{* * *}\end{array}$} \\
\hline & No & 25 (71.4) & $19(52.8)$ & \\
\hline \multirow{4}{*}{ Boys' age (y) } & 10 & $7(20.0)$ & $13(36.1)$ & \multirow{4}{*}{$\begin{array}{c}t=2.490 \\
d f=2 \\
P=0.288^{*}\end{array}$} \\
\hline & 11 & $14(40.0)$ & $13(36.1)$ & \\
\hline & 12 & $14(40.0)$ & $10(27.8)$ & \\
\hline & & $11.20 \pm 0.75$ & $10.91 \pm 0.80$ & \\
\hline \multirow{3}{*}{ Boys' grade } & Fourth & $7(20.0)$ & $13(36.1)$ & \multirow{3}{*}{$\begin{array}{c}\chi^{2}=2.490 \\
d f=2 \\
P=0.288^{* * *}\end{array}$} \\
\hline & Fifth & $14(40.0)$ & $13(36.1)$ & \\
\hline & Sixth & $14(40.0)$ & $10(27.8)$ & \\
\hline
\end{tabular}

* Independent Samples t-test; ** Fischer's Exact test; *** Chi-squared test 
Table 3. Self-awareness and its dimensions in the intervention and control groups

\begin{tabular}{|c|c|c|c|c|}
\hline \multirow{2}{*}{$\begin{array}{l}\text { Self-awareness } \\
\text { and Its Dimensions }\end{array}$} & \multirow[t]{2}{*}{ Groups } & \multicolumn{2}{|c|}{ Mean $\pm S D$} & \multirow{2}{*}{$\begin{array}{l}\text { Independent Samples } \\
\text { t-test Results }\end{array}$} \\
\hline & & Control & Intervention & \\
\hline \multirow{2}{*}{$\begin{array}{c}\text { Private } \\
\text { self-awareness }\end{array}$} & Pre-test & $21.11 \pm 7.11$ & $18.47 \pm 6.84$ & $t=1.59, d f=69, P=0.11$ \\
\hline & Post-test & $20.05 \pm 6.57$ & $22.66 \pm 5.40$ & $t=1.82, d f=69, P=0.07$ \\
\hline \multicolumn{2}{|c|}{ Paired Samples t-test result } & $t=1.71, d f=34, P=0.09$ & $t=3.11, d f=35, P=0.004$ & \\
\hline \multirow{2}{*}{$\begin{array}{c}\text { Public } \\
\text { self-awareness }\end{array}$} & Pre-test & $14.91 \pm 5.40$ & $12.27 \pm 5.01$ & $t=2.13, d f=69, P=0.03$ \\
\hline & Post-test & $15.11 \pm 5.57$ & $17.19 \pm 3.95$ & $F=9.703^{*}, P<0.001$ \\
\hline \multicolumn{2}{|c|}{ Paired Samples t-test result } & $t=0.43, d f=34, P=0.66$ & $t=4.42, d f=35, P<0.001$ & \\
\hline \multirow{2}{*}{ Social anxiety } & Pre-test & $11.28 \pm 4.20$ & $11.02 \pm 5.62$ & $t=0.21, d f=69, P=0.82$ \\
\hline & Post-test & $11.88 \pm 3.78$ & $13.97 \pm 7.23$ & $t=1.51, d f=69, P=0.13$ \\
\hline \multicolumn{2}{|c|}{ Paired Samples t-test result } & $\mathrm{t}=0.83, \mathrm{df}=34, \mathrm{P}=0.41$ & $t=1.80, d f=35, P=0.08$ & \\
\hline \multirow{2}{*}{$\begin{array}{c}\text { Total } \\
\text { self-awareness }\end{array}$} & Pre-test & $47.31 \pm 12.45$ & $41.77 \pm 10.59$ & $t=2.02, d f=69, P=0.04$ \\
\hline & Post-test & $47.05 \pm 11.76$ & $53.83 \pm 8.43$ & $\mathrm{~F}=87.471^{*}, \mathrm{P}<0.001$ \\
\hline \multicolumn{2}{|c|}{ Paired Samples t-test result } & $\mathrm{t}=0.78, \mathrm{df}=34, \mathrm{P}=0.43$ & $t=6.71, d f=35, P<0.001$ & \\
\hline
\end{tabular}

Table 4. The scores of self-efficacy and its dimensions in the intervention and control groups

\begin{tabular}{|c|c|c|c|c|}
\hline \multirow{2}{*}{$\begin{array}{l}\text { Self-awareness } \\
\text { and Its Dimensions }\end{array}$} & \multirow[t]{2}{*}{ Groups } & \multicolumn{2}{|c|}{ Mean $\pm S D$} & \multirow{2}{*}{$\begin{array}{l}\text { Independent Samples } \\
\text { t-test Results }\end{array}$} \\
\hline & & Control & Intervention & \\
\hline \multirow{2}{*}{ Social self-efficacy } & Before & $22.65 \pm 4.34$ & $21.11 \pm 4.70$ & $t=1.43, d f=69, P=0.15$ \\
\hline & After & $22.37 \pm 4.11$ & $24.22 \pm 3.59$ & $t=2.02, d f=69, P=0.04$ \\
\hline \multicolumn{2}{|c|}{ Paired t-test result } & $t=1.06, d f=34, P=0.29$ & $t=10.85, d f=35, P<0.001$ & \\
\hline \multirow{2}{*}{$\begin{array}{l}\text { Academic } \\
\text { self-efficacy }\end{array}$} & Before & $25.71 \pm 4.98$ & $23.63 \pm 4.22$ & $t=1.89, d f=69, P=0.06$ \\
\hline & After & $25.48 \pm 5.22$ & $25.50 \pm 4.11$ & $t=0.01, d f=69, P=0.99$ \\
\hline \multicolumn{2}{|c|}{ Paired t-test result } & $t=0.76, d f=34, P=0.44$ & $t=6.59, d f=35, P<0.001$ & \\
\hline \multirow{2}{*}{$\begin{array}{l}\text { Emotional } \\
\text { self-efficacy }\end{array}$} & Before & $17.31 \pm 4.66$ & $17.13 \pm 3.84$ & $t=0.17, d f=69, P=0.86$ \\
\hline & After & $17.28 \pm 4.64$ & $20.72 \pm 3.02$ & $t=3.67, d f=58.22, P<0.001$ \\
\hline \multicolumn{2}{|c|}{ Paired t-test result } & $t=0.10, d f=34, P=0.92$ & $t=7.87, d f=35, P<0.001$ & \\
\hline \multirow{2}{*}{ Total self-efficacy } & Pre-test & $65.68 \pm 11.33$ & $61.88 \pm 9.29$ & $t=1.54, d f=69, P=0.12$ \\
\hline & Post-test & $65.14 \pm 12.01$ & $70.44 \pm 8.12$ & $t=2.17, d f=59.53, P=0.03$ \\
\hline \multicolumn{2}{|c|}{ Paired Samples t-test result } & $t=1.59, d f=34, P=0.12$ & $t=10.95, d f=35, P<0.001$ & \\
\hline
\end{tabular}


In their study on the effect of self-awareness education on the self-efficacy and sociotropy autonomy characteristics of nurses in a psychiatry clinic, Ahmed and Elmasri (2011) found that self-awareness education program improved the study samples' self-efficacy. The tool used in this research was SEC-C by Jerusalem \& Schwarzer (1992). Likewise, Engin \& Cam (2009) explored the effect of a self-awareness education program on the selfefficacy of nurses. There was a statistically significant difference in the studied nurses' mean self-efficacy and sociotropy autonomy scores before and after receiving the education for increasing their self-awareness. Numerous studies also have supported that self-awareness training increased self-efficacy (Hatami et al. 2016; Sevari \& Manshedavi 2015; Umaru \& Umma 2015; Ahmed \& Elmasri 2011; Engin \& Cam 2009).

Children need to share their personal concerns with others. Children who fail to realize the effective presence of their parents or significant others in their life, lack efficacy. Family, as the safest social basis of mankind, plays the most effective role in the process of personality formation and self-efficacy in children. Various studies indicated that intervention programs that focus on parent education are effective in improving parent-child communication. Given the above explanation and the traditional role of mothers in our country, by educating self-awareness skills to mothers in the present study, they established more effective relationships with their children. As a result, self-awareness skill has increased boys' self-efficacy by affecting mothers and effectively communicating with their children. It is suggested that similar studies be conducted on single-parent families and their children according to gender and assess the effect of selfawareness training on both of parents, separately.

In this study, mothers' self-awareness positively affected their sons' self-efficacy. Thus, self-awareness enabled mothers to identify and become aware of the emotions of their own and their children's and pay more attention to interacting with their children. These findings help school health nurses in providing a proper educational environment with the collaboration of mothers who are the head of the family.

\section{Ethical Considerations}

\section{Compliance with ethical guidelines}

This study was approved by the Ethics Committee of Iran University of Medical Sciences (IUMS) (Code: IR.IUMS.REC.1397.099). It was registered at the Iranian Registry of Clinical Trials (IRCT) (Code:
IRCT20180615040109N1). All participating signed the informed consent.

\section{Funding}

The current study was part of a MSc. Thesis of Maliheh Aziznejad in the Department of Community Health Nursing, School of Nursing, and Midwifery of IUMS.

\section{Authors' contributions}

Conceptualization: Maliheh Azizinezhad, Sara Janmohammadi, Marhamat Farahaninia; Methodology: Maliheh Azizinezhad, Sara Janmohammadi, Hamid Haghani; Investigation: Maliheh Azizinezhad; Writing the original draft: Maliheh Azizinezhad, Sara Janmohammadi; Marhamat Farahaninia; Writing review and editing: Maliheh Azizinezhad, Marhamat Farahaninia, Sara Janmohammadi; and Supervision: Sara Janmohammadi.

\section{Conflict of interest}

The authors declared no conflicts of interest

\section{Acknowledgments}

The authors appreciate IUMS for its financial support. The Faculty of Nursing and Midwifery, Vice-Chancellor for research of IUMS, Shahre Ray administration of education, school principals, as well as the mothers and students involved in the study, are also appreciated.

\section{References}

Abbasi, S., Asgari, Z. \& Mehrabi, T., 2015. [Relationships between parenting styles of women working in hospitals and preschooler's anxiety, isolation and aggression (Persian)]. Iranian Journal of Nursing Research, 10(2), pp. 63-71. https://www.sid.ir/en/ journal $/$ ViewPaper. aspx?id=458655

Ahmed, H. A. \& Elmasri, Y. M., 2011. Effect of self-awareness education on the self-efficacy and sociotropy autonomy characteristics of nurses in a psychiatry clinic. Life Science Journal, 8(2), pp. 853-63. [DOI:10.32598/jccnc.3.2.125]

Chabok, M., Kashaninia, Z. \& Haghani, H., 2017. The relationship between spiritual health and general self-efficacy in the Iranian elderly. Journal of Client-Centered Nursing Care, 3(2), pp. 125-32. [DOI:10.32598/jccnc.3.2.125]

Delbary, T., 2015. [The relationship between perfectionism and selfefficacy of mothers with social skills of students (Persian) [MSc. thesis]. Islamic Azad University of Tehran.

Engin, E. \& Cam, O., 2009. Effect of self-awareness education on the self-efficacy and sociotropy autonomy characteristics 
of nurses in a psychiatry clinic. Archives of Psychiatric Nursing, 23(2), pp. 148-56. [DOI:10.1016/j.apnu.2008.05.003] [PMID]

Eslami, R., et al. 2013. [Effectiveness of group reality therapy on happiness and quality of life in unsupervised adolescents in Mashhad (Persian)]. Medical Journal of Mashhad University of Medical Sciences, 56(5), pp. 300-6. https://www.sid.ir/en/jour$\mathrm{nal} /$ ViewPaper.aspx?id=384821

Fenigstein, A., Scheier, M. F. \& Buss, A. H., 1975. Public and private self-consciousness: Assessment and theory. Journal of Consulting and Clinical Psychology, 43(4), pp. 522-27. [DOI:10.1037/ h0076760]

Gardner, D. M., 2011. Parents' influence on child social self-efficacy and social cognition [MSc. thesis]. Milwaukee: Marquette University. http://epublications.marquette.edu/cgi

Ghaemi, A., 2007. [Role of mother in education (Persian)]. Qom: Daroltabligh Eslami.

Grant, J. P., 2001. Situation of children in the world. New York: United Nations International Children's Emergency Fund (UNICEF).

Hatami, F., et al. 2016. [The effect of self-awareness training with painting on self-efficacy among orphaned adolescents (Persian)]. Practice in Clinical Psychology, 4(2), pp. 89-96. [DOI:10.15412/J.JPCP.06040203]

Hosseini, N., et al. 2008. [Research questionnaires in psychology, counseling, educational sciences and sociology (Persian)].Tehran: Sokhan.

Jahani Maleki, S., et al. 2011. [The relationship between level of knowledge of life skills and self-efficacy beliefs in students of Shahid Beheshti University (Persian)]. Journal of Modern Psychological Research, 6(22), pp. 26-56. https://www.sid.ir/en/journal $/$ ViewPaper.aspx?id=212985

Jerusalem, M. \& Schwarzer, R., 1992. Self-Efficacy As a Resource Factor in Stress Appraisal Processes. In R. Schwarzer (ed.), Selfefficacy: Thought Control Of Action. Washington DC: Hemisphere.

Latifian, M. \& Seif, D., 2007. [The Effect of self-awareness on students' interpersonal relationships disorders (Persian)]. Journal of Social and Human Sciences of Shiraz University, 26(3), pp. $137-$ 50. https:/ / www.sid.ir/fa/journal/ViewPaper.aspx?id=82324

Muris, P., 2001. A brief questionnaire for measuring self-efficacy in youths. Journal of Psychopathology and Behavioral Assessment, 23(3), pp. 145-9. [DOI:10.1023/A:1010961119608]

Muris, P., 2002. Relationships between self-efficacy and symptoms of anxiety disorders and depression in a normal adolescent sample. Personality and Individual Differences, 32(2), pp. 33748. [DOI:10.1016/S0191-8869(01)00027-7]

Nelson, B. L., 2013. Divorce mediation and its impact on children [MSc. thesis]. St: Catherine University. https://sophia.stkate. $\mathrm{edu} / \mathrm{msw}$ papers $/ 240$

Niknam, N., 2011. [Relationship of family relationship model and classroom structure with self-efficacy dimensions (Persian)] [MSc. thesis]. Shiraz: University of Shiraz.

Piri, R. \& Adib, Y., 2009. [Optimal pattern for pre-school courses curriculum (Persian)]. Journal of Instruction and Evaluation, 2(5), pp. 53-82. https://www.sid.ir/en/journal/ViewPaper. aspx?id $=189508$
Sahraian, M., Solhi, M. \& Haghani, H., 2012. [The effect of bloom empowerment model on life skills promotion in girl students at the third grade of high school in Jahrom (Persian)]. Journal of Research and Health, 2(1), pp. 9-18. https://www.sid.ir/en/ journal/ViewPaper.aspx?id=250577

Sevari, K. \& Manshedavi, S., 2015. [The efficacy of self-awareness training on reduction of internet addiction and loneliness and increase of self-efficacy (Persian)]. Clinical Psychology Studies, 2(22), pp. 163-79. https://www.sid.ir/en/journal/ViewPaper. aspx?id $=543249$

Sharifnasab, M. \& Sadrizade, N., 2011. [Study skills training self awarenessin fiction for children (Persian)]. Adolescent Monthly, 1(1), pp. 58-66. http://noo.rs/LpMmn

Tahmassian, K. \& Anari, A., 2009. [The relation between domains of self-efficacy and depression in adolescence (Persian)]. Journal of Applied Psychology, 3(1), pp. 83-93. https://www.sid.ir/en/ journal $/$ ViewPaper.aspx?id=196547

Taklavi, S., 2012. [Training mothers in play therapy and its effects on the behavior problems of learning disabled children (Persian)]. Journal of Learning Disability, 1(1), pp. 44-59. https:/ / www.sid.ir/en/journal/ViewPaper.aspx?id=231037

Tork-Ladani, F., et al. 2013. [The effect of life skills training of mothers of elementary school children on childhood behavioral problems (Persian)]. Galen Medical Journal, 2(2), pp. 76-9. https://www.gmj.ir/index.php/gmj/article/view/62/51

Umaru, Y. \& Umma, A., 2015. Effect of instruction in emotional intelligence skills on locus of control and academic self-efficacy among junior secondary school students in Niger State, Nigeria. Journal of Education And Practice, 6(18), pp. 164-9. https:// eric.ed.gov $/$ ?id=EJ1079778

Yousefzadeh, M. R., Yaghoobi, A. \& Rashidi, M., 2012. [The impact of metacognition skills instruction on secondary school girl students' self-efficacy (Persian)]. Journal of School Psychology, 1(3), pp. 118-33. https:/ / www.sid.ir/en/Journal/ViewPaper.aspx?ID $=276371$

Zajeri, A., 2011. [The effect of life skills training on compatibility among high school male students in Shiraz (Persian)]. [MSc. thesis]. Marvdasht: Islamic Azad University. https:/ / ganj-old. irandoc.ac.ir/articles/544911 
This Page Intentionally Left Blank 